\title{
Componentes agronômicos e produtividade do milho em diferentes sistemas de produção
}

\section{Agronomic components and maize productivity in different production systems}

\author{
Durval Nolasco das Neves Neto ${ }^{1}$, Antônio Clementino dos Santos ${ }^{2}$, Perlon Maia dos Santos ${ }^{3}$, Aridouglas dos Santos Araújo ${ }^{4}$, \\ Leonardo Bernardes Taverny de Oliveira ${ }^{5}$
}

Resumo: A crescente competitividade no setor rural exige a substituição do modelo produtivo tradicional por sistemas que possibilitem a maximização do uso do solo. Objetivou-se avaliar os componentes produtivos da cultura do milho em diferentes sistemas de produção em dois anos agrícolas. Os tratamentos foram constituídos por milho solteiro no sistema convencional e via integração com cultivares de Urochloa e sistema de rotação de cultura milho/milheto no primeiro ano agrícola e milho no segundo. O delineamento experimental foi em blocos casualizados, em esquema fatorial 3x $2+1$, com quatro repetições. As variáveis avaliadas foram: tamanho e diâmetro de espiga, número de linhas e grãos por espiga, peso de mil grãos, estande final de plantas e produção de grãos de milho por planta e hectare. Os dados quando significativos foram comparadas pelo teste $\mathrm{F}$ ao nível de 5\% de probabilidade de erro. Em relação ao tratamento adicional, foi utilizado o teste de Dunnett a 5\% de significância. Os sistemas integrados com cultivares de Urochloa brizanthae e o sistema com rotação de cultura não promoveram alterações nos componentes produtivos da cultura do milho, além de melhorar a produtividade ao longo do tempo e promovem melhorias nas características químicas do solo. A Urochloa brizantha cv. Marandu e Piatã demonstraram seu potencial e viabilidade em sistema em sistema integrado em Neossolo Quartzarênico.

Palavras-chave: Cultivo consorciado; Integração lavoura-pecuária; Rotação de cultura; Sistema sustentável.

\begin{abstract}
Growing competitiveness in the rural sector requires the replacement of the traditional productive model with systems that make it possible to maximize land use. The objective of this study was to evaluate the production components of corn in different production systems in two years. The treatments consisted of single maize in the conventional system and via integration with cultivars of Urochloa and rotation system of maize/millet crop in the first agricultural year and corn in the second. The experimental design was in randomized blocks, in a $3 \times 2+1$ factorial scheme, with four replications. The variables evaluated were: spike size and diameter, number of rows and grains per ear, weight of one thousand grains, final plant stand and corn grain yield per plant and hectare. The significant data were compared by the F test at the 5\% error probability level. Regarding the additional treatment, the Dunnett test was used at 5\% significance level. The integrated systems with cultivars of Urochloa brizanthae and the system with crop rotation did not promote changes in the maize crop production components, besides improving productivity over time and promoting improvements in soil chemical characteristics. The Urochloa brizantha cv. Marandu and Piatã demonstrated their potential and viability in an integrated system in Quartzarenic Neosol.
\end{abstract}

Key words: Intercropping, Crop-livestock, Crop rotation, Sustainable system.

\footnotetext{
*Autor para correspondência

Recebido para publicação em 24/11/2015; aprovado em 10/03/2016

${ }^{1}$ Prof. Dr. em Ciência Animal Tropical, Instituto Tocantinense Presidente Antônio Carlos, ITPAC, Araguaína, Tocantins, E-mail: durval.nolasco@ gmail.com

${ }^{2}$ Prof. Dr., Programa de Pós-Graduação em Ciência Animal Tropical, Universidade Federal do Tocantins, UFT, E-mail: clementino@mail.uft.edu.br

${ }^{3}$ Prof. Dr. em Ciência Animal Tropical, Universidade Federal Rural da Amazônia, UFRA, E-mail: perllon_zoo@yahoo.com.br

${ }^{4}$ Dr. em Ciência Animal Tropical, Serviço Nacional de Aprendizagem Rural, SENAR, E-mail: aridouglas_araujo@hotmail.com

${ }^{5}$ Prof. Dr. em Ciência Animal Tropical, Faculdade de Ensino Superior da Amazônia Reunida, FESAR, E-mail: tavernyzoot@yahoo.com.br
} 


\section{INTRODUÇÃO}

Algumas tecnologias buscam, não somente frear a queda da sustentabilidade da produção das pastagens, mas também promover o desenvolvimento do setor rural, através da maior geração de empregos e diminuição dos riscos no sistema de produção, por intermédio da diversificação do uso do solo, como alternativa de sustentabilidade da agropecuária e a conservação do meio ambiente (BALBINOT JÚNIOR et al., 2009; MACEDO, 2009). Assim, sistemas que integram lavoura e pecuária, sistema de plantio direto e sistemas agroflorestais estão tomando destaque no cenário mundial (NEVES NETO et al., 2015b).

O sistema de integração lavoura-pecuária, surge como alternativa para se alcançar essas premissas, sustentabilidade e desenvolvimento do setor rural, envolvendo o cultivo de culturas anuais e a produção pecuária em pastejo, visando gerar resultados socioeconômicos e ambientais positivos. Estas vantagens se tornam possíveis devido ao uso sucessivo e contínuo das áreas, ao aumento de rendimento agrícola e pecuário e à redução de custos de produção, proporcionados pelas melhorias químicas, físicas e biológicas do solo (FRANZLUEBBERS, 2007; CONTE et al., 2011).

Dentre as modalidades de integração lavoura-pecuária utilizadas no Brasil, destaca-se o cultivo consorciado de espécies forrageiras tropicais, como a Urochloa brizantha com culturas como milho, milheto, sorgo, soja e arroz (SILVA et al., 2008). Nesse sistema, a forrageira tem a função de fornecer alimento para a exploração pecuária, a partir do final do período chuvoso e/ou, posteriormente, de formação de palhada para o cultivo da cultura produtora de grãos, em sistema plantio direto (BORGHI; CRUSCIOL,2007).

O sistema integrado de produção tem sido objeto de estudo por vários pesquisadores (FREITAS et al., 2008;
CRUZ et al., 2009; PARIZ et al., 2011) os quais relataram que, no geral, a presença da forrageira não diminuiu a produtividade de grãos de milho. Mesmo sendo alvo de diversos estudos, a maioria dos trabalhos com sistemas integrados avaliam a utilização do capim-Marandu, Urochloa decumbens e ruziziensis sob Latossolo Amarelo e Vermelho, faltando informações e trabalhos utilizando novos cultivares em Neossolo Quartzarênico.

Buscando respaldar o sistema de integração lavourapecuária, objetivou-se avaliar a influência do sistema de rotação milho/milheto/milho e sistemas integrados com Urochloa brizantha (Syn. Brachiaria brizantha) cv. Marandu e Piatã sobre os componentes produtivos da cultura do milho em dois anos sucessivos de produção, além das características químicas do solo e a viabilidade de utilização dos cultivares Marandu e Piatã nesses sistemas produtivos em Neossolo Quartzarênico.

\section{MATERIAL E MÉTODOS}

O estudo foi conduzido na Escola de Medicina Veterinária e Zootecnia da Universidade Federal do Tocantins - UFT, Araguaína - TO, nas coordenadas geográficas $07^{\circ} 12$ '28" Sul e 48 12 '26" Oeste. A vegetação natural é caracterizada pelo ecótono Floresta Amazônica-Cerrado. A altitude média é de $240 \mathrm{~m}$ e o clima da região, segundo a classificação Köppen, é AW - Tropical de verão úmido, com estação seca e chuvosa bem definida e precipitação média anual de $1800 \mathrm{~mm}$. A área utilizada estava sob pousio de pousio de dois anos e meio, tendo vegetação predominante de plantas espontâneas rasteiras. Os dados das variáveis ambientais foram coletados mensalmente, durante o período experimental (Tabela 1), na Estação Agrometeorológica localizada na UFT, Araguaína - TO.

Tabela 1. Médias mensais da temperatura máxima, mínima e média, insolação e precipitação pluvial no período experimental.

\begin{tabular}{|c|c|c|c|c|c|c|}
\hline Ano/Mês & Variável & Temp. Máx. $\left({ }^{\circ} \mathrm{C}\right)$ & $\begin{array}{c}\text { Temp. } \\
\text { Mín. }\left({ }^{\circ} \mathrm{C}\right)\end{array}$ & $\begin{array}{c}\text { Temp. Méd. } \\
\left({ }^{\circ} \mathrm{C}\right)\end{array}$ & $\begin{array}{l}\text { Insol. } \\
\text { (Horas) }\end{array}$ & $\begin{array}{l}\text { Precip. } \\
(\mathrm{mm})\end{array}$ \\
\hline \multirow{5}{*}{2011} & Janeiro & 31,1 & 21,5 & 25,2 & 128,9 & 280,8 \\
\hline & Fevereiro & 30,7 & 21,3 & 24,7 & 99,6 & 295,1 \\
\hline & Março & 31,3 & 21,9 & 25,5 & 137,5 & 239,2 \\
\hline & Abril & 30,9 & 21,5 & 25,2 & 147,3 & 202,1 \\
\hline & Dezembro & 30,7 & 21,2 & 25,5 & 131,4 & 110,9 \\
\hline Média $\pm d p$ & & $30,9 \pm 0,3$ & $21,5 \pm 0,3$ & $25,2 \pm 0,3$ & $128,9 \pm 17,9$ & $225,6 \pm 73,8$ \\
\hline \multirow{3}{*}{2012} & Janeiro & 29,7 & 21,1 & 24,5 & 83,5 & 304,4 \\
\hline & Fevereiro & 30 & 20,3 & 24,2 & 79,3 & 266,3 \\
\hline & Março & 31,2 & 20,8 & 25,1 & 144 & 170,1 \\
\hline Média $\pm \mathrm{dp}$ & & $30,3 \pm 0,8$ & $20,7 \pm 0,4$ & $24,6 \pm 0,5$ & $102,3 \pm 36,2$ & $246,9 \pm 69,2$ \\
\hline
\end{tabular}

(Temp. Máx.) Temperatura máxima; (Temp. Mín.) Temperatura mínima; (Temp. Méd.) Temperatura média; (Insol.) Insolação; (Precip.) Precipitação; (dp) Desvio padrão.

O solo da área foi classificado como Neossolo Quartzarênico Órtico típico (EMBRAPA, 2013), com textura arenosa. Para caracterização inicial foram realizadas amostragens na camada de $0-20 \mathrm{~cm}$ e para a análise final das características químicas do solo foram coletadas amostras nas camadas de 0-10 e 10-20 cm. Foram realizadas as seguintes avaliações químicas: fósforo $(\mathrm{P})$ e potássio $\left(\mathrm{K}^{+}\right)$extraíveis em Melich $^{-1}\left(\mathrm{mg} \mathrm{dm}^{-3}\right)$, matéria orgânica (M.O.) $\left(\mathrm{g} \mathrm{dm}^{-3}\right), \mathrm{pH}$ $\left(\mathrm{CaCl}_{2}\right)$, cálcio $\left(\mathrm{Ca}^{2+}\right)$, magnésio $\left(\mathrm{Mg}^{2+}\right)$ e alumínio $\left(\mathrm{Al}^{3+}\right)$ trocáveis e acidez potencial $(\mathrm{H}+\mathrm{Al})$. Com os valores obtidos nas análises do solo foram calculadas a saturação por bases (V\%) e a saturação por alumínio $(\mathrm{m} \%)$. As análises foram conduzidas no Laboratório de Solo do curso de Zootecnia/PGCAT/UFT, de acordo com as recomendações da EMBRAPA (2009), conforme resultados na Tabela 2. Posteriormente a caracterização do solo foi realizada a correção com 1,5 toneladas ha-1 de calcário (PRNT 88\%, $\mathrm{CaO} 30 \%$ e $\mathrm{MgO}$ 18\%), seguida de aração e gradagem. 
Tabela 2. Características químicas do solo na camada de $0-20 \mathrm{~cm}$.

\begin{tabular}{|c|c|c|}
\hline Variáveis & & Resultados \\
\hline $\mathrm{pH}$ & $\mathrm{CaCl}_{2}$ & 4,30 \\
\hline $\mathrm{P}$ & \multirow{2}{*}{$\mathrm{mg} \mathrm{dm^{-3 }}$} & 1,14 \\
\hline $\mathrm{K}$ & & 2,00 \\
\hline $\mathrm{Ca}$ & \multirow{4}{*}{$\mathrm{cmol}_{\mathrm{c}} \mathrm{dm}^{-3}$} & 1,24 \\
\hline $\mathrm{Mg}$ & & 0,47 \\
\hline $\mathrm{Al}$ & & 0,19 \\
\hline $\mathrm{H}+\mathrm{Al}$ & & 3,82 \\
\hline MO & $\mathrm{g} \mathrm{dm}^{-3}$ & 15,97 \\
\hline SB & \multirow{3}{*}{$\mathrm{cmol}_{\mathrm{c}} \mathrm{dm}^{-3}$} & 1,72 \\
\hline $\mathrm{CTC}_{\mathrm{pH} 7,0}$ & & 5,54 \\
\hline $\mathrm{CTC}_{\mathrm{Ef}}$ & & 1,91 \\
\hline $\mathrm{V}$ & \multirow{2}{*}{$\%$} & 30,99 \\
\hline $\mathrm{m}$ & & 11,27 \\
\hline
\end{tabular}

(P) Fósforo; (K) Potássio; (Ca) Cálcio; (Mg) Magnésio; (Al) Alumínio; (H+Al) Acidez potencial; (MO) Matéria orgânica; (SB) Soma de bases; (CTC $\left.{ }_{\mathrm{pH}} 7,0\right)$ Capacidade de Troca de Cátions; (CTC Ef) Capacidade Efetiva de Troca de Cátions; (V) Saturação por Bases; (m) Saturação por Alumínio.

Foram trabalhados quatro sistemas produtivos: milho em sistema convencional em parcelas de $225 \mathrm{~m}^{2}(15 \mathrm{x} 15 \mathrm{~m})$, sendo as áreas mantidas em pousio entre os anos agrícolas; milho integrado com Urochloa brizantha cv. Marandu e Piatã em subdivisões de $56,25 \mathrm{~m}^{2}(7,5 \times 7,5 \mathrm{~m})$, as áreas de pastagens formadas no primeiro ano agrícola foram mantidas no segundo ano e a integração no segundo ano agrícola foram implantadas em áreas que vinham do sistema convencional; e rotação de cultura milho seguido de milheto no primeiro ano agrícola e milho no segundo ano agrícola.

$\mathrm{O}$ delineamento experimental foi em blocos casualizados, em esquema fatorial $(3 \times 2+1)$. O primeiro fator: três sistemas de produção (convencional, integração com Urochloa brizantha cv. Marandu ou Piatã); o segundo fator: dois anos agrícolas (2010/2011 e 2011/2012); o tratamento adicional: rotação de cultura, com quatro repetições.

A Semeadura do milho foi efetuada manualmente em sulcos de $5 \mathrm{~cm}$ de profundidade com espaçamento entre linhas de $0,80 \mathrm{~m}$, sendo utilizado a variedade Robusto. Após 20 dias de semeadura foi realizado desbaste nas linhas com a finalidade de ajustar a população de plantas para cinco plantas por metro linear, resultando em 62.500 plantas ha $^{-1}$. As plantas de milho foram colhidas quando a "linha de leite" estava com $50 \%$ do grão. No controle de plantas espontâneas, realizou-se capina manual aos 20 dias após a semeadura em todos os tratamentos.

A implantação dos sistemas integrados, quando foram incluídas as Urochloa brizantha cv. Marandu e Piatã, se deram 21 dias após a semeadura da cultura do milho e utilizou-se linhas duplas para as braquiárias, espaçadas $30 \mathrm{~cm}$ da cultura anual e $20 \mathrm{~cm}$ entre as linhas da gramínea forrageira.

Em relação ao milheto, foi utilizada o híbrido de duplo propósito ADR 7020, sendo a semeadura efetuada manualmente em sulcos de $5 \mathrm{~cm}$ de profundidade com espaçamento entre linhas de $0,40 \mathrm{~m}$ e densidade de 20 sementes puras viáveis por metro linear. Após, a área formada, o material não foi retirado, mandando-o como cobertura do solo.

Em ambas as adubações, formação e cobertura, foram utilizadas como fonte de Nitrogênio, $\mathrm{P}_{2} \mathrm{O}_{5}$ e $\mathrm{K}_{2} \mathrm{O}$ a uréia, superfosfato simples e cloreto de potássio, respectivamente. A adubação fosfatada, em todos os tratamentos, foi feita a lanço de forma homogenia em toda a parcela. Enquanto o Nitrogênio e o Potássio foram aplicados rentes às linhas da cultura do milho, respeitando o cronograma de atividades (Tabela 3 ).

Tabela 3. Cronograma das atividades de plantio, colheita e adubação ( $\mathrm{kg} \mathrm{ha}^{-1}$ ) em função dos sistemas de produção nos anos agrícolas.

\begin{tabular}{|c|c|c|c|c|c|c|c|c|c|}
\hline \multicolumn{2}{|c|}{ Atividade } & \multicolumn{2}{|c|}{ Manejo } & \multicolumn{6}{|c|}{ Adubação } \\
\hline \multirow{2}{*}{\multicolumn{2}{|c|}{ Tratamento }} & Plantio & Colheita & $\mathrm{N}$ & & $\mathrm{P}_{2} \mathrm{C}$ & & $\mathrm{K}_{2} \mathrm{O}$ & \\
\hline & & \multicolumn{2}{|c|}{ Data } & Data & Qt. & Data & Qt. & Data & Qt. \\
\hline \multirow{3}{*}{ G-AI } & Con. & $21 / 1 / 11$ & $20 / 4 / 11$ & $4 / 2 ; 20 / 2 ; 29 / 3 / 11$ & 120 & $20 / 1 / 11$ & 100 & $20 / 1 ; 19 / 2 ; 30 / 3 / 11$ & 120 \\
\hline & Mar. & $21 / 1 / 11$ & $20 / 4 / 11$ & $4 / 2 ; 20 / 2 ; 29 / 3 / 11$ & 120 & $20 / 1 / 11$ & 100 & $20 / 1 ; 19 / 2 ; 30 / 3 / 11$ & 120 \\
\hline & Piatã & $21 / 1 / 11$ & $20 / 4 / 11$ & $4 / 2 ; 20 / 2 ; 29 / 3 / 11$ & 120 & $20 / 1 / 11$ & 100 & $20 / 1 ; 19 / 2 ; 30 / 3 / 11$ & 120 \\
\hline \multirow{3}{*}{ G-AII } & Con. & $5 / 12 / 11$ & $4 / 3 / 12$ & $20 / 12 / 11 ; 4 / 1 ; 16 / 2 / 12$ & 120 & $1 / 12 / 11$ & 100 & $4 / 12 / 11 ; 3 / 1 ; 15 / 2 / 12$ & 120 \\
\hline & Mar. & $5 / 12 / 11$ & $4 / 3 / 12$ & $20 / 12 / 11 ; 4 / 1 ; 16 / 2 / 12$ & 120 & $1 / 12 / 11$ & 100 & $4 / 12 / 11 ; 3 / 1 ; 15 / 2 / 12$ & 120 \\
\hline & Piatã & $5 / 12 / 11$ & $4 / 3 / 12$ & $20 / 12 / 11 ; 4 / 1 ; 16 / 2 / 12$ & 120 & $1 / 12 / 11$ & 100 & $4 / 12 / 11 ; 3 / 1 ; 15 / 2 / 12$ & 120 \\
\hline
\end{tabular}

Data com final (11) ano de 2011; Data com final (12) ano de 2012; (G-AI) Milho do ano agrícola de 2010/2011; (G-AII) Milho do ano agrícola de 2011/2012; (Con.) Plantio convencional; (Mar.) Plantio integrado com Marandu; (Piatã) Plantio integrado com Piatã; (Qt.) Quantidade de fertilizante em kg ha ${ }^{-1}$.

Os componentes produtivos avaliados foram: comprimento de espiga (CE), diâmetro de espiga (DE), número de fileiras de grãos por espiga (NFE), número de grãos por espiga (NGE), peso de mil grãos (PMG), estande final de plantas (EFP), produção de grãos por planta (PGP) e produção de grãos por hectare (PGH).

$\mathrm{O}$ estande final de plantas foi calculado através do número de plantas na área útil da parcela, 7,2 m² (3,0 x 2,4 
m), no momento da colheita, valor transformado em plantas $\mathrm{ha}^{-1}$. Após a colheita das espigas mensurou-se: o comprimento e diâmetro de espigas, com o auxílio de régua; número de fileiras de grãos e número de grãos por espigas, aferição manual; peso de mil grãos, quando submetida à estufa a $60^{\circ} \mathrm{C}$ e ventilação forçada, até o material atingir peso constante. A produtividade de grãos por planta foi mensurada quando se fez a contagem de grãos por espiga, e a produtividade por hectare pela pesagem dos grãos da área útil de cada parcela, posteriormente extrapolando os valores para a área de um hectare, após a realização da correção de umidade dos grãos para $13 \%$.

Os dados foram submetidos à análise estatística pelo teste $\mathrm{F}$ a $5 \%$ de probabilidade de erro para os efeitos principais e do desdobramento da interação quando necessário. Em relação ao tratamento adicional, quando significativos $(\mathrm{P}<0,05)$ foi realizada a comparação pelo teste de Dunnett a $5 \%$ de probabilidade de erro.

\section{RESULTADOS E DISCUSSÃO}

De maneira geral, observam-se melhorias nas características química do solo em todos os sistemas de produção ao final do ano agrícola de 2011/2012 (Tabela 4). De acordo com a CFSMG (1999) a acidez do solo passou de muito elevada, no início do estudo, para elevada ao final do período experimental; o fósforo e potássio, mesmo mantendo concentração muito baixa, apresentou expressiva melhoria ao final do estudo; o cálcio e magnésio que apresentavam baixa concentração passaram a ter média concentração; com exceção do sistema de rotação de cultura que manteve concentração de alumínio muito baixa, os demais sistemas de produção tiveram uma elevação na concentração de alumínio (baixo), porém todos os sistemas de produção apresentaram diminuição de acidez potencial, a qual era classificada como média e passou a ser baixa; a matéria orgânica e soma de bases obtiveram consideráveis melhorias, passando da classificação baixa para média; devido à elevada acidez potencial inicial a capacidade de troca de cátions apresentou redução na sua classificação, no entanto a capacidade efetiva de troca de cátions passou de baixa para média; a saturação por bases obteve melhora, passando de médio para bom e; a saturação por alumínio acompanhou o resultados da concentração de alumínio, elevação da classificação para baixo dos sistemas de produção, com exceção da rotação de cultura, que manteve sua classificação em muito baixa.

Tabela 4. Características químicas do solo no final do segundo ano agrícola em função dos sistemas de produção.

\begin{tabular}{|c|c|c|c|c|c|c|c|}
\hline Variáveis & Formação & Conv. & Mar. & Piat. & $\mathrm{M} / \mathrm{M}$ & DMS & $\mathrm{CV}(\%)$ \\
\hline & & \multicolumn{6}{|c|}{ 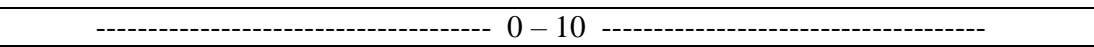 } \\
\hline $\mathrm{pH}$ & $\mathrm{CaCl}_{2}$ & 4,55 & 4,60 & 4,72 & 4,75 & 0,42 & 4,09 \\
\hline $\mathrm{P}$ & \multirow{2}{*}{$\mathrm{mg} \mathrm{dm}^{-3}$} & 3,41 & 3,09 & 3,25 & 3,03 & 0,87 & 12,36 \\
\hline $\mathrm{K}$ & & 4,00 & 5,50 & 5,50 & 12,00 & 3,68 & 24,69 \\
\hline $\mathrm{Ca}$ & \multirow{4}{*}{$\mathrm{cmol}_{\mathrm{c}} \mathrm{dm}^{-3}$} & 1,47 & 1,53 & 1,63 & 1,60 & 0,67 & 19,37 \\
\hline $\mathrm{Mg}$ & & 0,60 & 0,59 & 0,49 & 0,66 & 0,48 & 37,00 \\
\hline $\mathrm{Al}$ & & 0,25 & 0,25 & 0,22 & 0,15 & 0,30 & 62,80 \\
\hline $\mathrm{H}+\mathrm{Al}$ & & 1,77 & 1,86 & 1,85 & 1,56 & 0,76 & 19,43 \\
\hline MO & $\mathrm{g} \mathrm{dm}^{-3}$ & 26,28 & 26,05 & 26,98 & 36,36 & 11,43 & 17,89 \\
\hline SB & \multirow{3}{*}{$\mathrm{cmol}_{\mathrm{c}} \mathrm{dm}^{-3}$} & 2,08 & 2,13 & 2,13 & 2,29 & 1,03 & 21,61 \\
\hline $\mathrm{CTC}_{\mathrm{pH} 7,0}$ & & 3,85 & 3,99 & 3,99 & 3,85 & 0,74 & 8,56 \\
\hline $\mathrm{CTC}_{\mathrm{Ef}}$ & & 2,33 & 2,38 & 2,35 & 2,45 & 0,94 & 17,80 \\
\hline $\mathrm{V}$ & \multirow{2}{*}{$\%$} & 53,76 & 53,05 & 53,70 & 59,45 & 20,58 & 16,93 \\
\hline $\mathrm{m}$ & & 11,65 & 10,89 & 9,23 & 6,44 & 14,16 & 67,07 \\
\hline & & \multicolumn{6}{|c|}{ 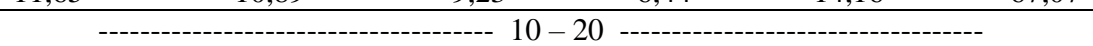 } \\
\hline $\mathrm{pH}$ & $\mathrm{CaCl}_{2}$ & 4,32 & 4,57 & 4,62 & 4,70 & 0,54 & 5,40 \\
\hline $\mathrm{P}$ & \multirow{2}{*}{$\mathrm{mg} \mathrm{dm}{ }^{-3}$} & 2,21 & 2,06 & 2,01 & 1,98 & 1,27 & 27,87 \\
\hline $\mathrm{K}$ & & 4,00 & 3,75 & 5,00 & 9,25 & 3,21 & 26,42 \\
\hline $\mathrm{Ca}$ & \multirow{4}{*}{$\mathrm{cmol}_{\mathrm{c}} \mathrm{dm}^{-3}$} & 1,06 & 1,40 & 1,15 & 1,45 & 1,04 & 37,20 \\
\hline $\mathrm{Mg}$ & & 0,40 & 0,47 & 0,51 & 0,60 & 0,32 & 29,12 \\
\hline $\mathrm{Al}$ & & 0,44 & 0,34 & 0,30 & 0,27 & 0,40 & 52,86 \\
\hline $\mathrm{H}+\mathrm{Al}$ & & 2,03 & 2,02 & 1,98 & 1,66 & 0,95 & 22,42 \\
\hline $\mathrm{MO}$ & $\mathrm{g} \mathrm{dm}^{-3}$ & 26,90 & 27,21 & 25,12 & 26,13 & 12,16 & 20,89 \\
\hline SB & \multirow{3}{*}{$\mathrm{cmol}_{\mathrm{c}} \mathrm{dm}^{-3}$} & 1,47 & 1,88 & 1,68 & 2,08 & 1,26 & 32,01 \\
\hline $\mathrm{CTC}_{\mathrm{pH} 7,0}$ & & 3,49 & 3,90 & 3,66 & 3,74 & 1,06 & 12,96 \\
\hline $\mathrm{CTC}_{\mathrm{Ef}}$ & & 1,90 & 2,22 & 1,98 & 2,36 & 1,12 & 24,03 \\
\hline $\mathrm{V}$ & \multirow{2}{*}{$\%$} & 42,08 & 46,90 & 46,28 & 55,80 & 25,86 & 24,50 \\
\hline $\mathrm{m}$ & & 23,74 & 16,77 & 15,91 & 11,81 & 22,43 & 59,50 \\
\hline
\end{tabular}

(Conv.) Sistema convencional; (Mar.) Sistema integrado com Marandu; (Piat.) Sistema integrado com Piatã; (M/M) Rotação de cultura com milho/milheto/milho; (DMS) Diferença mínima significativa; (CV) Coeficiente de variação; (P) Fósforo; (K) Potássio; (Ca) Cálcio; (Mg) Magnésio; (Al) Alumínio; (H+Al) Acidez potencial; (MO) Matéria orgânica; (SB) Soma de bases; (CTC ${ }_{\mathrm{pH}}$ 7,0) Capacidade de Troca de Cátions; (CTC Ef) Capacidade Efetiva de Troca de Cátions; (V) Saturação por Bases; (m) Saturação por Alumínio.

Os resultados das características químicas do solo, observados na Tabela 4, ressaltam o potencial real dos sistemas produtivos de integração lavoura-pecuária e rotação de culturas em proporcionar melhorias ao ecossistema solo. Dentre outros fatores, essas expressivas melhorias nas características químicas do solo, são permitidas pela utilização de protocolos de adubações eficientes, além da continua inclusão de resíduos orgânicos no solo (FRANZLUEBBERS, 2007; FLORES et al., 2008; CARVALHO et al., 2010). 
No primeiro ano agrícola (2010/2011) o milho levou 88 dias para ser colhido, enquanto que no segundo ano agrícola (2011/2012) o milho foi colhido aos 91 dias após a semeadura. Mesmo o ciclo produtivo do milho sendo influenciado por fatores extrínsecos as plantas, tais fatores como manejo, solo e clima (SHARRATT; MCWILLIANS, 2005; RESENDE et al., 2008), os quais acabam influenciando no número de dias para colheita. Este apresentou pequena variação em seu ciclo produtivo, mostrando que os fatores climáticos, os quais tiveram boa distribuição em ambos os anos agrícolas (Tabela 1), e os sistemas de produção, dentro de cada ano agrícola, não influenciaram a quantidade de dias para o milho ser colhido.
O comprimento e o diâmetro de espiga, aliados ao número de fileiras, grãos por espiga e peso de mil grãos, são características, que acabam influenciando a produtividade de grãos por planta, consequentemente, por área. Neste contexto, em que há certa interação entre as características agronômicas da cultura do milho, e estas são influenciadas não somente por fatores edafoclimáticos, mas também pela ação antrópica. À avaliação dos componentes produtivos desta gramínea cereal tiveram efeitos diferenciados em função do ano agrícola (2010/2011 ou 2011/2012), no entanto, não foram influenciados pelos sistemas de produção (convencional, integração com Marandu ou Piatã) (Tabela 5).

Tabela 5. Teste $\mathrm{F}$ das variáveis: comprimento de espiga, diâmetro de espiga, número de fileiras de grãos por espiga, número de grãos por espiga, peso de mil grãos, estande final de plantas, produção de grãos por planta e produção de grãos por hectare de milho em função dos sistemas de produção nos anos agrícolas.

\begin{tabular}{|c|c|c|c|c|c|c|c|c|}
\hline Fatores & CE & $\mathrm{DE}$ & NFE & NGE & PMG & EFP & PGP & PGH \\
\hline Anos & $40,566^{* *}$ & $56,127 * *$ & $0,549^{\mathrm{ns}}$ & $48,306 * *$ & $4,135^{\mathrm{ns}}$ & $12,839 * *$ & $34,971 * *$ & $34,855 * *$ \\
\hline Sis. Pro. & $2,444^{\mathrm{ns}}$ & $0,512^{\mathrm{ns}}$ & $0,099^{\mathrm{ns}}$ & $0,974^{\mathrm{ns}}$ & $0,932^{\mathrm{ns}}$ & $3,554^{\mathrm{ns}}$ & $2,399^{\mathrm{ns}}$ & $1,581^{\mathrm{ns}}$ \\
\hline Interação & $0,028^{\mathrm{ns}}$ & $3,246^{\mathrm{ns}}$ & $1,945^{\mathrm{ns}}$ & $1,489^{\mathrm{ns}}$ & $0,837^{\mathrm{ns}}$ & $0,025^{*}$ & $2,600^{\mathrm{ns}}$ & $1,193^{\mathrm{ns}}$ \\
\hline $\mathrm{A} / \mathrm{S} \times \mathrm{M} / \mathrm{M}$ & $11,365^{++}$ & $13,112^{++}$ & $0,023^{\mathrm{ns} *}$ & $18,996^{++}$ & $2,743^{\mathrm{ns} *}$ & $0,204^{\mathrm{ns} *}$ & $10,903^{++}$ & $4,518^{+}$ \\
\hline
\end{tabular}

"* Significativo ao nível de $1 \%$ de significância; ${ }^{*}$ Significativo ao nível de $5 \%$ de significância; ${ }^{\text {ns }}$ Não significativo para o teste $\mathrm{F}$ ao nível de $5 \%$ de
significância; ${ }^{++}$Significativo ao nível de $1 \%$ de significância; ${ }^{+}$Significativo ao nível de $5 \%$ de significância; ${ }^{\text {ns* }}$ Não significativo para o teste de Dunnett ao nível de 5\% de significância; (Anos) Anos agrícolas de 2010/2011 e 2011/2012; (Sis. Pro.) Sistema de produção; (Interação) Interação anos agrícolas vs sistema de produção; (A/SxM/M) Comparação das médias dos anos agrícolas e sistemas de produção com a rotação de cultura com milho/ milheto/milho.

Analisando os dados médios obtidos no estudo, em relação ao comprimento e diâmetro de espiga, nota-se, desempenho parecido em ambas as variáveis. Estas foram influenciadas $(\mathrm{P}<0,05)$ apenas pelos anos agrícolas, e não pelos métodos de produção, tendo maiores valores no ano
2011/2012. Este resultado é reforçado, quando se observa o desempenho do tratamento adicional, o qual, independente do sistema produtivo e em ambas as variáveis, não diferem $(\mathrm{P}>0,05)$ dos valores obtidos no segundo ano agrícola (Tabela 6).

Tabela 6. Comprimento de espiga e diâmetro de espiga de milho em função dos sistemas de produção nos anos agrícolas.

\begin{tabular}{|c|c|c|c|c|c|}
\hline \multicolumn{6}{|c|}{$\mathrm{CE}(\mathrm{cm})$} \\
\hline & Convencional & Marandu & Piatã & Média & $\mathrm{CV}(\%)$ \\
\hline Ano I & $11,50^{--}$ & $11,71^{--}$ & $12,05^{--}$ & $11,75 \mathrm{~b}$ & \\
\hline Ano II & $12,90^{+}$ & $13,18^{+}$ & $13,57^{+}$ & $13,22 \mathrm{a}$ & \\
\hline Média & 12,20 & 12,45 & 12,81 & & 4,45 \\
\hline $\mathrm{M} / \mathrm{M}$ & & & & & \\
\hline \multicolumn{6}{|c|}{$\mathrm{DE}(\mathrm{cm})$} \\
\hline Ano I & $3,90^{--}$ & $3,68^{--}$ & $3,73^{--}$ & $3,77 \mathrm{~b}$ & \\
\hline Ano II & $4,10^{+}$ & $4,19^{+}$ & $4,18^{+}$ & $4,16 \mathrm{a}$ & 317 \\
\hline Média & 4,00 & 3,93 & 3,96 & & 3,17 \\
\hline $\mathrm{M} / \mathrm{M}$ & \multicolumn{4}{|c|}{4,21} & \\
\hline
\end{tabular}

Médias seguidas de mesma letra (maiúsculas nas colunas e minúsculas nas linhas) não diferem entre si para o teste $\mathrm{F}$ ao nível de 5\% de significância; Médias seguidas de ${ }^{+}$não diferem e ${ }^{-}$diferem entre si para o teste de Dunnett ao nível de 5\% de significância. (Ano I) Ano agrícola de 2010/2011; (Ano II) Ano agrícola de 2011/2012; (M/M) Rotação de cultura com milho/milheto/milho.

O número de fileiras de grãos por espiga e o peso de mil grãos não foram influenciados $(\mathrm{P}>0,05)$ pelos anos de semeadura e pelos métodos de produção (Tabela 7). O número de fileiras de grãos tem grande controle genético, o que confere a esta característica pouca influência dos fatores externos. O peso de mil grãos possui maior susceptibilidade aos fatores do meio, quando esses são limitantes ao desenvolvimento da planta, o que não foi observado no presente estudo (FREITAS et al., 2013). 
Tabela 7. Número de fileiras de grãos por espiga e peso de mil grãos de milho em função dos sistemas de produção nos anos agrícolas.

\begin{tabular}{|c|c|c|c|c|c|}
\hline \multicolumn{6}{|c|}{ NFE } \\
\hline & Convencional & Marandu & Piatã & Média & $\mathrm{CV}(\%)$ \\
\hline Ano I & $12,74^{--}$ & $12,29^{--}$ & $12,32^{--}$ & 12,45 & \\
\hline Ano II & $12,37^{--}$ & $12,63^{--}$ & $12,77^{--}$ & 12,59 & \\
\hline Média & 12,56 & 12,46 & 12,54 & & 3,63 \\
\hline $\mathrm{M} / \mathrm{M}$ & & & & & \\
\hline \multicolumn{6}{|c|}{$\frac{12,56}{\mathrm{PMG}(\mathrm{g})}$} \\
\hline Ano I & $286,75^{--}$ & $269,38^{--}$ & $286,43^{--}$ & 280,85 & \\
\hline Ano II & $265,51^{--}$ & $267,62^{--}$ & $270,86^{--}$ & 268,00 & 5,69 \\
\hline Média & 276,13 & 268,50 & 278,65 & & \\
\hline $\mathrm{M} / \mathrm{M}$ & \multicolumn{4}{|c|}{260,57} & \\
\hline
\end{tabular}

Médias seguidas de mesma letra (maiúsculas nas colunas e minúsculas nas linhas) não diferem entre si para o teste $\mathrm{F}$ ao nível de 5\% de significância; Médias seguidas de ${ }^{+}$não diferem e ${ }^{-}$diferem entre si para o teste de Dunnett ao nível de 5\% de significância. (Ano I) Ano agrícola de 2010/2011; (Ano II) Ano agrícola de 2011/2012; (M/M) Rotação de cultura com milho/milheto/milho.

O número de grãos por espiga, se mostrou superior ( $\mathrm{P}<0,05)$ no ano agrícola de 2011/2012, em relação ao de 2010/2011 (Tabela 8). No número de grãos, o tratamento adicional acompanhou os resultados expressos no comprimento e diâmetro de espiga, não diferiu $(\mathrm{P}>0,05)$ dos sistemas convencional e integrado no segundo ano agrícola (Tabela 6). As melhoras no meio de crescimento das plantas de milho, no segundo ano agrícola, possibilitaram redução da competição intraespecífica por fotoassimilados e interespecífica por fatores de crescimento, principalmente no estádio de florescimento da cultura, o que acaba explicando os melhores resultados no segundo ano produtivo (CALONEGO et al., 2011; FREITAS et al., 2013).

Tabela 8. Número de grãos por espiga de milho em função dos sistemas de produção nos anos agrícolas.

\begin{tabular}{|c|c|c|c|c|c|}
\hline \multicolumn{6}{|c|}{ NGE } \\
\hline Fatores & Convencional & Marandu & Piatã & Média & $\mathrm{CV}(\%)$ \\
\hline Ano I & $259,10^{--}$ & $240,94^{--}$ & $250,61^{--}$ & $250,22 b$ & \\
\hline Ano II & $310,02^{+}$ & $321,55^{+}$ & $347,05^{+}$ & $326,20 \mathrm{a}$ & 001 \\
\hline Média & 284,56 & 281,24 & 298,83 & & 9,01 \\
\hline $\mathrm{M} / \mathrm{M}$ & & & & & \\
\hline
\end{tabular}

Médias seguidas de mesma letra (maiúsculas nas colunas e minúsculas nas linhas) não diferem entre si para o teste $\mathrm{F}$ ao nível de 5\% de significância; Médias seguidas de ${ }^{+}$não diferem e ${ }^{-}$diferem entre si para o teste de Dunnett ao nível de 5\% de significância. (Ano I) Ano agrícola de 2010/2011; (Ano II) Ano agrícola de 2011/2012; (M/M) Rotação de cultura com milho/milheto/milho.

Os componentes produtivos estão alocados distintamente dentro dos estádios fenológicos da cultura do milho (SILVA et al., 2008). Desta forma, o número de fileiras de grãos por espiga é determinado no estádio fenológico 1; o comprimento de espiga e número de grãos por espiga nos estádios fenológicos 3,4 e 5 e; o peso de mil grãos está associado ao estádio fenológico 6. A restrição nutricional e hídrica, ou outras condições adversas, dentro desses estádios fenológicos, podem comprometer o bom desenvolvimento dos seus componentes produtivos (SILVA et al., 2008; CHIODEROLI et al., 2010). Fato este, acaba que corroborando com os resultados do presente estudo, em que, as variáveis avaliadas não foram influenciadas pelos fatores climáticos (Tabela 1), tão pouco pelos sistemas de produção, mas sim, pelas melhorias das características químicas do solo (Tabela 4) promovida pela inclusão no sistema dos restos culturais do ano anterior (BALBINOT JÚNIOR et al., 2009; CARVALHO et al., 2010).

Esse processo de inclusão no sistema dos restos culturais e, consequente melhoria das características químicas do solo, explica o aumento do comprimento e diâmetro de espiga do primeiro para o segundo ano agrícola (Tabela 6). O aumento do número de grãos por espiga no ano agrícola de 2011/2012 é consequência do aumento do comprimento e diâmetro de espiga (Tabelas 6 e 8), pois estas variáveis estão correlacionadas (LOPES et al., 2007).

$\mathrm{O}$ arranjo espacial das plantas de milho, bem como o espaçamento entre linhas e o estande final de plantas promoveram melhor desenvolvimento das plantas e, consequentemente, maior competição com a forrageira (BORGHI; CRUSCIOL, 2007; MAIA et al., 2015). Isto levou a não diferenciação $(\mathrm{P}>0,05)$ entre os métodos de produção para as características produtivas do milho, pois, é sabido que plantas espaçadas equidistantes minimizam sua competição por nutrientes, luz, água e outros fatores, contribuindo para o melhor desenvolvimento das espigas.

A não diferenciação dos componentes morfológicos da espiga, entre os sistemas de produção (Tabelas 6, 7 e 8), são condizentes com os normalmente encontrados na literatura (PARIZ et al., 2009; PEREIRA et al., 2009; RICHART et al., 2010; PARIZ et al., 2011), mesmo sendo realidades diferentes, pois a maioria dos trabalhos são desenvolvidos sob Latossolo Amarelo e Vermelho. 
O estande final de plantas foi a única variável que apresentou interação entre os anos agrícolas $v s$ sistemas de produção (Tabela 5). Mesmo havendo tendência de maiores números de plantas no sistema convencional, entre os sistemas de produção, não houve diferença $(\mathrm{P}>0,05)$ em relação a quantidade final de plantas, em ambos os anos agrícolas (Tabela 9)

Tabela 9. Estande final de plantas de milho em função dos sistemas de produção nos anos agrícolas.

\begin{tabular}{|c|c|c|c|c|c|}
\hline \multicolumn{6}{|c|}{ Estande final de plantas (planta ha ${ }^{-1}$ ) } \\
\hline Fatores & Convencional & Marandu & Piatã & Média & $\mathrm{CV}(\%)$ \\
\hline Ano I & $55.555,75 \mathrm{Ba}^{+}$ & $52.083,50 \mathrm{Aa}^{+}$ & $52.430,75 \mathrm{Aa}^{+}$ & $53.356,67$ & \\
\hline Ano II & $60.416,75 \mathrm{Aa}^{+}$ & $56.597,25 \mathrm{Aa}^{+}$ & $56.597,50 \mathrm{Aa}^{+}$ & $57.870,50$ & 556 \\
\hline Média & $57.986,25$ & $54.340,38$ & $54.514,13$ & & (5, \\
\hline $\mathrm{M} / \mathrm{M}$ & \multicolumn{4}{|c|}{$54.861,25$} & \\
\hline
\end{tabular}

Médias seguidas de mesma letra (maiúsculas nas colunas e minúsculas nas linhas) não diferem entre si para o teste $\mathrm{F}$ ao nível de 5\% de significância; Médias seguidas de ${ }^{+}$não diferem e ${ }^{-}$diferem entre si para o teste de Dunnett ao nível de 5\% de significância. (Ano I) Ano agrícola de 2010/2011; (Ano II) Ano agrícola de 2011/2012; (M/M) Rotação de cultura com milho/milheto/milho.

Dentro de cada sistema de produção, os integrados com Urochloa brizantha cv. Marandu e Piatã apresentaram o mesmo desempenho, não diferiram $(\mathrm{P}>0,05)$ entre os anos de produção. No entanto, o sistema convencional de produção apresentou maior $(\mathrm{P}<0,05)$ número final de plantas no ano agrícola de 2011/2012 (Tabela 9).

Como nas outras variáveis, o estande final de plantas, não apresentou diferença $(\mathrm{P}>0,05)$ entre os sistemas de produção, corroborando com os resultados encontrados na literatura (SILVA et al., 2008; CRUZ et al., 2009; PARIZ et al., 2009).
Quando se analisa de forma conjunta os resultados obtidos no estudo (Tabelas 6, 7, 8, 9 e 10), observa-se, que a maior produção de grãos por planta e por hectare no ano agrícola de 2011/2012, em relação ao de 2010/2011, e a não diferenciação $(\mathrm{P}>0,05)$ dos sistemas de produção convencional, integrado e rotação de cultura no segundo ano agrícola (Tabela 10), são proporcionados, dentre outros fatores, pelo maior comprimento, diâmetro e número de grãos por espiga, além do maior estande final de plantas (Tabelas 6, 8 e 9$)$.

Tabela 10. Produção de grãos por planta e produção de grãos por hectare de milho em função dos sistemas de produção nos anos agrícolas.

\begin{tabular}{|c|c|c|c|c|c|}
\hline \multicolumn{6}{|c|}{ Produção de grãos por planta $\left(\right.$ g planta $\left.^{-1}\right)$} \\
\hline & Convencional & Marandu & Piatã & Média & $\mathrm{CV}(\%)$ \\
\hline Ano I & $0,074^{--}$ & $0,065^{--}$ & $0,072^{--}$ & $0,070 \mathrm{~b}$ & \\
\hline Ano II & $0,082^{+}$ & $0,086^{+}$ & $0,094^{+}$ & $0,087 \mathrm{a}$ & \\
\hline Média & 0,078 & 0,075 & 0,083 & & 8,68 \\
\hline $\mathrm{M} / \mathrm{M}$ & & & & & \\
\hline \multicolumn{6}{|c|}{ Produção de grãos por hectare $\left(\mathrm{kg} \mathrm{ha}^{-1}\right)$} \\
\hline Ano I & $4.125,87^{+}$ & $3.385,57^{--}$ & $3.764,61^{--}$ & $3.758,68 \mathrm{~b}$ & \multirow{4}{*}{11,89} \\
\hline Ano II & $4.938,30^{+}$ & $4.870,35^{+}$ & $5.326,47^{+}$ & $5.045,04 \mathrm{a}$ & \\
\hline Média & $4.532,08$ & $4.127,96$ & $4.545,54$ & & \\
\hline $\mathrm{M} / \mathrm{M}$ & \multicolumn{4}{|c|}{$5.014,53$} & \\
\hline
\end{tabular}

Médias seguidas de mesma letra (maiúsculas nas colunas e minúsculas nas linhas) não diferem entre si para o teste $\mathrm{F}$ ao nível de 5\% de significância; Médias seguidas de ${ }^{+}$não diferem e ${ }^{-}$diferem entre si para o teste de Dunnett ao nível de 5\% de significância. (Ano I) Ano agrícola de 2010/2011; (Ano II) Ano agrícola de 2011/2012; (M/M) Rotação de cultura com milho/milheto/milho.

O equilíbrio produtivo entre os sistemas de produção, observado no estudo, está de acordo com os resultados encontrados por Freitas et al. (2008), Pariz et al. (2009) e Richart et al. (2010), os quais, não observaram redução $(\mathrm{P}>0,05)$ na produção de grão entre os sistemas convencional e integrado com gramíneas forrageiras tropicais.

De modo geral, a manutenção da produtividade observada no presente estudo, em relação aos métodos de produção, foi proporcionada principalmente, pela introdução tardia dos cultivares de Urochloa brizantha no sistema, permitindo a planta de milho alcançar maior porte e arquitetura foliar propícia ao fechamento da entrelinha, diminuindo, assim, a incidência de luz, dificultando o estabelecimento da forrageira, o que acaba reduzindo a competitividade interespécies pelos fatores de crescimento (NEVES NETO et al., 2015a). Sabe-se que devido o metabolismo $\mathrm{C}_{4}$, característica que as tornam exigentes por luz, as Urochloa brizantha são influenciadas pelo sombreamento das culturas cereais (DIAS FILHO, 2002).

A melhora das variáveis produtivas e da produtividade de grãos no segundo ano agrícola, está relacionada, a já conhecida melhoria nas características químicas do solo, proporcionadas pelos sistemas de integração lavoura-pecuária e rotação de culturas (FRANZLUEBBERS, 2007; BALBINOT JÚNIOR et al., 2009; CARVALHO et al., 2010). Além disso, quanto melhor a fertilidade do solo, melhor o 
desenvolvimento do milho, consequentemente, maior seu poder de concorrência (RESENDE et al., 2008).

Esta melhora nas características químicas do solo, mediante inclusão dos restos culturais do ano anterior e, refletidas nas respostas produtivas do ano agrícola de 2011/2012, se dão de forma global, devido a matéria orgânica humificada. Estas substâncias húmicas promovem o armazenamento de água no solo e o fornecimento de nutrientes para o crescimento das plantas (CANELLAS et al., 2002; CALONEGO et al., 2012), pois sabe-se que estas substancias podem elevar significativamente a capacidade de troca catiônica, consequentemente, maior reserva de nutrientes minerais. Além de favorecer o aumento na área superficial do sistema radicular (CANELLAS et al., 2002; QUAGGIOTTI et al., 2004), o que acaba possibilitando a exploração de área maior de solo, aumentando a capacidade das plantas em obter água e nutrientes minerais.

Em Neossolo Quartzarênico, estas melhorias podem ser cruciais para a elevação dos índices produtivos ao longo dos anos agrícolas, pois segundo Frazão et al. (2008) os teores de carbono e de bases, no complexo sortivo do solo, são mais elevados em áreas com maior teor de argila e recém-abertas para o cultivo. Avelino et al. (2011) destacam a baixa capacidade de retenção de água do Neossolo Quartzarênico, além da menor retenção dos nutrientes disponibilizados via adubação.

A partir dos resultados, nota-se que não houve diferença $(\mathrm{P}>0,05)$ produtiva entre os sistemas estudados. No entanto, torna-se interessante observar que o sistema integrado com Urochloa brizantha cv. Marandu foi o que apresentou menor produtividade por área, este desempenho, pode ser associado ao potencial alelopático do capim-Marandu, além da capacidade de competição interespecífica de cada cultivar de Urochloa brizantha, consorciada com o milho, pois é sabido que o capim-Piatã apresenta estabelecimento mais lento do que o cultivar Marandu (VALLE et al., 2007). O que torna o capim-Marandu inicialmente mais competitivo pelos fatores de crescimento, fato maximizado pelo solo em que se desenvolveu o estudo. Entretanto, mesmo trabalhando em Neossolo Quartzarênico, todos os sistemas produtivos no segundo ano agrícola apresentaram produtividade média superior à da média do estado do Tocantins, que, na safra de 2011/2012, foi de $4.321 \mathrm{~kg} \mathrm{ha}^{-1}$ e da média nacional, que foi de $4.808 \mathrm{~kg} \mathrm{ha}^{-1}$ (CONAB, 2013).

\section{CONCLUSÕES}

Os sistemas de produção rotação de cultura e integração lavoura-pastagem, não influenciam de forma negativa os componentes produtivos da cultura do milho, além de promover melhorias na produtividade no segundo ano agrícola.

Sistemas de produção, independente se rotação de cultura ou integração, proporcionam melhorias nas características químicas do solo ao longo do tempo.

A Urochloa brizantha cv. Marandu e Piatã não reduzem os índices produtivos do milho, demonstrando seu potencial e viabilidade em sistema de integração lavoura-pastagem em Neossolo Quartzarênico.

\section{AGRADECIMENTOS}

Ao Programa de Apoio a Núcleos de Excelência PRONEX/SECT/CNPq (Edital SECT/CNPq N ${ }^{\circ}$ 08/2010 -
PRONEX). As Redes Nacionais de Pesquisa em Agrobiodiversidade e Sustentabilidade Agropecuária REPENSA/CNPq. E CAPES pela concessão da bolsa de estudo (Doutorado).

\section{REFERÊNCIAS}

AVELINO, P. M.; NEIVA, J. N. M.; ARAUJO, V. L.; ALEXANDRINO, E.; SANTOS, A. C.; RESTLE, J. Características agronômicas e estruturais de híbridos de sorgo em função de diferentes densidades de plantio. Revista Ciência Agronômica, Fortaleza, v.42, n.2, p.534-541, 2011.

BALBINOT JÚNIOR, A. A.; MORAES, A.; VEIGA, M.; PELISSAR, A.; DIECKOW, J. Integração lavoura-pecuária: intensificação de uso de áreas agrícolas. Ciência Rural, Santa Maria, v.39, n.6, p.1925-1933, 2009.

BORGHI, E.; CRUSCIOL, C. A. C. Produtividade de milho, espaçamento e modalidade de consorciação com Brachiaria brizantha em sistema plantio direto. Pesquisa Agropecuária Brasileira, Brasília, v.42, n.2, p.163-171, 2007.

CALONEGO, J. C.; GIL, F. C.; ROCCO, V. F.; SANTOS, E. A. Persistência e liberação de nutrientes da palha de milho, braquiária e labe-labe. Bioscience Journal, Uberlândia, v.28, n.5, p.770-781, 2012

CAlONEGO, J. C.; POLETO, L. C.; DOMINGUES, F. N.; TIRITAN, C. S. Produtividade e crescimento de milho em diferentes arranjos de plantas. Revista Agrarian, Dourados, v.4, n.12, p.84-90, 2011.

CANELLAS, L. P.; OLIVARES, F. L.; FAÇANHA, A. L. O.; FAÇANHA, A. R. Humic acids isolated from earthworm compost enhance root elongation, lateral root emergence, and plasma membrane $\mathrm{H}^{+}$-ATPase activity in maize roots. Plant Physiology, Rockville, v.130, n.4, p.1951-1957, 2002.

CARVALHO, P. C. F.; ANGHINONI, I.; MORAES, A.; SOUZA, E. D.; SULC, R. M.; LANG, C. R.; FLORES, J. P. C.; LOPES, M. L. T.; SILVA, J. L. S.; OSMAR CONTE, O.; WESP, C. L.; LEVIEN, R.; FONTANELI, R. S.; BAYER, C. Managing grazing animals to achieve nutrient cycling and soil improvement in no-till integrated systems. Nutrient Cycling in Agroecosystems, Ithaca, v.88, n.2, p.259-273, 2010.

CHIODEROLI, C. A.; MELLO, L. M. M.; GRIGOLLI, P. J.; SILVA, J. O. R.; CESARIN, A. L. Consorciação de braquiárias com milho outonal em plantio direto sob pivô central. Engenharia Agrícola, Jaboticabal, v.30, n.6, p.11011109,2010

Comissão de Fertilidade do Solo do Estado de Minas Gerais (CFSMG). Recomendações para o uso de corretivos e fertilizantes em Minas Gerais - $5^{\mathrm{a}}$ aproximação. Viçosa: CFSEMG, 1999. 359p.

Companhia Nacional de Abastecimento (CONAB). Acompanhamento da safra brasileira: grãos safra 2011/2012. 2013.

CONTE, O.; FLORES, J. P. C.; CASSOL, L. C.; ANGHINONI, I.; CARVALHO, P. C. F.; LEVIEN, R.; WESP, C. L. Evolução de atributos físicos de solo em sistema 
de integração lavoura-pecuária. Pesquisa Agropecuária Brasileira, Brasília, v.46, n.10, p.1301-1309, 2011

CRUZ, S. C. S.; PEREIRA, F. R. S.; BICUDO, S. J.; SANTOS, J. R.; ALBUQUERQUE, A. W.; MACHADO, C. G. Consórcio de milho e Brachiaria decumbens em diferentes preparos de solo. Acta Scientiarum. Agronomy, Maringá, v.31, n.4, p.633-639, 2009.

DIAS FILHO, M. B. Photosynthetic light response of $\mathrm{C}_{4}$ grasses Brachiaria brizantha in Brachiaria humidicola under shade. Scientia Agricola, Piracicaba, v.59, n.1, p.65-68, 2002.

Empresa Brasileira de Pesquisa Agropecuária (EMBRAPA). Centro Nacional de Pesquisa de Solos. Sistema brasileiro de classificação de solos. 3.ed. Brasília: Embrapa, 2013. 353p.

Empresa Brasileira de Pesquisa Agropecuária (EMBRAPA). Manual de análises químicas de solos, plantas e fertilizantes. 2.ed. Brasília: Embrapa comunicação para transferência de tecnologia, 2009. 627p.

FLORES, J. P. C.; CASSOL, L. C.; ANGHINONI, I.; CARVALHO, P. C. F. Atributos químicos do solo em função da aplicação superficial de calcário em sistema de integração lavoura-pecuária submetido a pressões de pastejo em plantio direto. Revista Brasileira de Ciência do Solo, Viçosa, v.32, p.2385-2396, 2008.

FRANZLUEBBERS, A. J. Integrated crop-livestock systems in the southeastern USA. Agronomy Journal, Madison, v.99, n.2, p.361-372, 2007.

FRAZÃO, L. A.; PÍCCOLO, M. C.; FEIGL, B. J.; CERRI, C. C.; CERRI, C. E. P. Propriedades químicas de um Neossolo Quartzarênico sob diferentes sistemas de manejo no Cerrado Mato-Grossense. Pesquisa Agropecuária Brasileira, Brasília, v.43, n.5, p.641-648, 2008.

FREITAS, F. C. L.; SANTOS, M. V.; MACHADO, A. F. L.; FERREIRA, L. R.; FREITAS, M. A. M.; SILVA, M. G. O. Comportamento de cultivares de milho no consórcio com Brachiaria brizantha na presença e ausência de foramsulfuron + iodosulfuron-methyl para o manejo da forrageira. Planta Daninha, Viçosa, v.26, n.1, p.215-221, 2008.

FREITAS, R. J.; NASCENTE, A. S.; SANTOS, F. L. S. População de plantas de milho consorciado com Urochloa ruziziensis. Pesquisa Agropecuária Tropical, Goiânia, v.43, n.1, p.79-87, 2013.

LOPES, S. J.; LÚCIO, A. D.; STORCK, L.; DAMO, H. P.; BRUM, B.; SANTOS, V. J. Relações de causa e efeito em espigas de milho relacionadas aos tipos de híbridos. Ciência Rural, Santa Maria, v.37, n.6, p.1536-1542, 2007.

MACEDO, M. C. M. Integração lavoura e pecuária: o estado da arte e inovações tecnológicas. Revista Brasileira de Zootecnia, Viçosa, v.38, p.133-146, 2009. (Supl. Especial).

MAIA, P. B.; REZENDE, I. S.; TSUMURA, F. H. Desempenho de híbridos de milho e da forrageira Brachiaria brizantha em cultivo consorciado. Revista Verde de Agroecologia e Desenvolvimento Sustentável, Pombal, v.10, n.1, p.81-87, 2015.
NEVES NETO, D. N.; SANTOS, A. C.; ALEXANDRINO, E.; SANTOS, P. M. Características morfogênicas e estruturais de Urochloa spp. sob manejo convencional e consorciado com cereais. Revista Ciência Agronômica, Fortaleza, v.46, n.1, p.204-215, 2015a.

NEVES NETO, D. N.; SANTOS, A. C.; SOUSA, L. F.; SANTOS, P. M.; ARAÚJO, A. S.; ALENCAR, N. M. Establishment of Urochloa brizantha cultivars intercropped with different cereal grains. Semina: Ciências Agrárias, Londrina, v.36, n.5, p.3353-3368, 2015b.

PARIZ, C. M.; ANDREOTTI, M.; AZENHA, M. V.; BERGAMASCHINE, A. F.; MELLO, L. M. M.; LIMA, R. C. Produtividade de grãos de milho e massa seca de braquiárias em consórcio no sistema de integração lavoura-pecuária. Ciência Rural, Santa Maria, v.41, n.5, p.875-882, 2011.

PARIZ, C. M.; ANDREOTTI, M.; TARSITANO, M. A. A.; BERGAMASCHINE, A. F.; BUZETTI, S.; CHIODEROLI, C. A. Desempenhos técnicos e econômicos da consorciação de milho com forrageiras dos gêneros Panicum e Brachiaria em sistema de integração lavoura-pecuária. Pesquisa Agropecuária Tropical, Goiânia, v.39, n.4, p.360-370, 2009.

PEREIRA, R. G.; ALBUQUERQUE, A. W.; CAVALCANTE, M.; PAIXÃO, S. L.; MARACAJÁ, P. B. Influência dos sistemas de manejo do solo sobre os componentes de produção do milho e Brachiaria decumbens. Revista Caatinga, Mossoró, v.22, n.1, p.64-71, 2009.

QUAGGIOTTI, S.; RUPERTI, B.; PIZZEGHELLO, D.; FRANCIOSO, O.; TUGNOLI, V.; NARDI, S. Effect of low molecular size humic substances on nitrate uptake and expression of genes involved in nitrate transport in maize (Zea mays L.). Journal of Experimental Botany, Lancaster, v.55, n.398, p.803-813, 2004.

RESENDE, A. V.; SHIRATSUCHI, L. S.; FONTES, J. R. A.; ARNS, L. L. K.; RIBEIRO, L. F. Adubação e arranjo de plantas no consórcio milho e braquiária. Pesquisa Agropecuária Tropical, Goiânia, v.38, n.4, p.269-275, 2008.

RICHART, A.; PASLAUSKI, T.; NOZAKI, M. H.; RODRIGUES, C. M.; FEY, R. Desempenho do milho safrinha e da Brachiaria ruziziensis cv. Comum em consórcio. Revista Brasileira de Ciências Agrárias, Recife, v.5, n.4, p.497-502, 2010.

SHARRATT, B. S.; MCWILLIAMS, D. A. Microclimatic and rooting characteristics of narrow-row versus conventional-row corn. Agronomy Journal, Madison, v.97, n.4, p.1129-1135, 2005.

SILVA, E. T.; CUNHA, J. L. X. L.; MADALENA, J. A. S.; SILVA, J. A. C.; SILVA, W. T. Produção de milho (Zea mays L.) em consórcios com gramíneas forrageiras. Revista Caatinga, Mossoró, v.21, n.4, p.29-34, 2008.

VALLE, C. B.; EUCLIDES, V. P. B.; VALÉRIO, J. R.; MACEDO, M. C. M.; FERNANDES, C.D.; DIAS FILHO, M.B. Brachiaria brizantha cv. Piatã: uma forrageira para diversificação de pastagens tropicais. Seed News, Pelotas, v.11, n.2, p.28-30, 2007. 